\title{
Optimal operation of hybrid High Voltage Direct Current and Alternating Current networks based on OPF combined with droop voltage control
}

Mònica Aragüés-Peñalba, Joan Sau Bassols, Samuel Galceran Arellano, Andreas Sumper, Oriol Gomis Bellmunt

Centre d'Innovació Tecnològica en Convertidors Estàtics i Accionaments (CITCEA-UPC), Departament d'Enginyeria Elèctrica, Universitat Politècnica de Catalunya.

ETS d'Enginyeria Industrial de Barcelona, Av. Diagonal, 647, Pl. 2. 08028 Barcelona, Spain

\begin{abstract}
This study focuses on the operation and control of HVDC multi-terminal systems that transmit the power being generated in offshore wind farms to the terrestrial AC grids. The aim of the paper is to propose and validate an algorithm to ensure optimal operation of HVDC-HVAC systems. This algorithm is implemented in a central controller that, knowing the electrical characteristics of the $\mathrm{DC}$ and $\mathrm{AC}$ systems, the power generation from the wind farms and the power demand, executes periodically an AC/DC Optimal Power Flow (OPF) and sends the appropriate voltage references to the grid side converter's control. The voltage control of the DC grid is distributed and based on droop law, implemented in grid side converters. The droop offset is modified periodically so as to adapt to the actual operating conditions and ensure optimal operation according to a specified objective function. Dynamic simulations show the system optimal operation in terms of loss minimization under wind speed changes, loss of communications and demand variation. These results are validated experimentally after implementing the control scheme in an HVDC scaled experimental platform. Dynamic simulations are also performed to show that the system can still be operated based on the proposed strategy even during contingencies implying the disconnection of a power system element (converter and DC cable).
\end{abstract}

Keywords: HVDC-HVAC, OPF, distributed control, droop control 


\section{Introduction}

The wind power statistics corroborate the increase of wind installations during the last years. According to the European Wind Energy Association (EWEA), 12,800 MW of wind power capacity was installed and grid-connected in the EU during 2015 [1]. From the new installations, 9,766 MW were installed onshore and 3,034 MW offshore. The wind power installed in 2015 was larger than any other form of power generation the same year (it accounted for $44.2 \%$ of total 2015 power capacity installations). All these data point to an encouraging future for the wind industry, but, onshore locations with the best wind profiles are finite and most of them occupied by finished projects or under development. To face this problem, there are basically two solutions allowing to continue increasing the wind power contribution in the energy mix despite the saturation of the best terrestrial sites. One promotes the reuse of wind turbines that occupy the best locations replacing them by other wind turbines of larger power and with more advanced technologies. The old wind turbines can be then allocated in other sites, facilitating and expanding the use of renewable energy. The other solution is based on continuing exploiting the offshore sites. Focusing on the latter, the installation of wind farms in offshore sites, does not only represent an alternative to terrestrial locations, but also offers more favourable wind profiles (more constant and less turbulent). It has often lower social opposition due to its lower visual impact and allows the installation of larger wind turbines (and, thus, with larger rated power). Depending on the distance that separates the offshore wind farm from the terrestrial grid, it may be more interesting for technical and economical reasons, to use High Voltage Direct Current (HVDC) instead of High Voltage Alternating Current (HVAC) transmission [2]. Taking this into account, the transmission system is likely to merge interconnections with both HVDC and HVAC. The resulting transmission system can include a number of different AC and DC systems and each subsystem can include multiple terminals.

One of the challenges in HVDC multi-terminal systems is the distribution of the power flows in the HVDC grid, ensured through DC voltage control. A classification and comparison of the voltage control methods for HVDC grids is investigated in [3]. A special focus has been given to distributed control of the DC voltage from different converters [4] and, in particular, to DC voltage droop control $[5,6]$. The power flows in HVDC grids connected to HVAC systems have 
been analysed in literature and several methodologies have been proposed to ensure optimal operation of the whole system, ranging from centralized strategies to distributed. Many studies have been focusing on optimal power flows either in AC grids or in DC grids [7-9] addressing existing challenges in terms of mathematical modelling, convergence, computation time or global solution guarantees. All these aspects are specially significant in AC power flows, showing, in general, more complexity due to its non linear, non convex and large scale nature [10]. However, some studies do analyse the operation of AC and DC grids coupled. For instance, the impact of DC links on the convergence of $\mathrm{AC} / \mathrm{DC}$ power flows is addressed in [11]. On the other hand, a method which derives the voltage droop settings to minimize the adverse effect of a disturbance on the DC side is proposed in [12] considering AC system stability.

The optimal operation of hybrid AC-DC systems is addressed in $[13,14]$ covering several optimization goals and with different levels of accuracy when modelling the power system elements and their losses. Optimal (economic) operation of hybrid HVDC-HVAC systems taking into account contingencies has been proposed through a Security Constrained Optimal Power Flow approach in [15-17]. In all the cases [13-17], the analysis are performed from a steady-state point of view. Therefore, the before cited studies address OPF in AC-DC systems, but do not study its integration with distributed controls and its dynamic performance. On the other hand, the existing studies addressing the dynamic performance of HVDC multi-terminal systems based on OPF (for instance [6]), do not include their connection and power interaction with the AC system on their formulation and do neither show the impact of eventual contingencies.

Taking into account the previous gap, the present work addresses the OPF for hybrid systems considering its integration with distributed controls and the effect of communications. For this purpose, the OPF formulation for HVAC-HVDC systems detailed in [14] (only analysed in steady state) is expanded, proposing an OPF to be executed periodically as a centralized high hierarchy control that sends the appropriate references to a distributed lower level control. The developed control scheme enables to optimally operate HVDC-HVAC systems under normal operation and under contingencies implying the loss of one of the system elements.

In order to ensure optimal operation, the central controller knows the electrical characteristics of the whole system (and therefore, its admittance matrix) and receives periodically the wind power 
farm generation and the power demand. So, one of the advantages of using a centralized controller is that it can collect the information of different devices of the system to operate it optimally. The drawback is that it requires a communication system. Therefore, the proposal is to operate the system based on a centralized control sending signals to local controls or distributed controls. These distributed controls are responsible for achieving the references received to optimally operate the system. In this system, the distributed controls correspond to the converters and generating units controls. In grid side converters, voltage droop ensures the voltage control of the HVDC system and reactive power control allows to exchange the required reactive power with the $\mathrm{AC}$ grids, providing reactive power support if needed. The active and reactive power controls of the generating units perform primary and secondary control functions of the AC system to keep voltage and frequency within limits. The distributed controls do also ensure stable operation when communications are lost. Additionally, it is shown that the proposed control scheme can also deal with contingencies.

To the best knowledge of the authors, the combination of a centralized OPF with distributed controls for operating HVDC-HVAC systems taking into account the effect of communications and eventual contingencies has not been analysed in literature. The main contributions of the study are listed next. First, a novel methodology which combines centralized and distributed controls is proposed for operating HVDC-HVAC systems and it is implemented for minimizing losses, including transmission and converter losses. Dynamic simulations show how the methodology leads to stable operation and loss minimization in different scenarios, like wind power variation and demand changes. Second, the operation strategy proposed is shown to be able to deal with contingencies including the loss of a power system element or the loss of the communication system. Third, the methodology proposed is validated experimentally. The results obtained through dynamic simulations and experimentally for wind power variation, loss of communications and demand variation coincide, verifying the operation in real time of a hybrid DC-AC system in a scaled laboratory platform. Dynamic simulations are also presented to show that the proposed control scheme does not compromise the system operation if a contingency occurs, like the disconnection of a converter or DC cable. Last, but not least, the effect of wind power measurements uncertainty on the control scheme performance is analysed. 


\section{Optimization problem}

The optimization problem solved periodically by the central controller involves DC and AC power systems and can be thus, considered as a non-linear constrained optimization type. Mainly two strategies can be used to solve DC and AC power flows: sequential and unified. The sequential approach [18] separates the problem in two parts corresponding each one to DC and AC power flow equations, respectively. Unified approach, [19] solves all the equations together.

The optimal power flow tool here presented is based on a unified strategy. Several objective functions can be defined in this optimization tool. An interesting one is the overall losses in the HVDC-HVAC network, including transmission and converter losses. This objective function is the one used to show the system performance in Section 4.1. The general layout of an HVDC-HVAC transmission system to which the tool is applied is shown in Fig. 1.

The converter topology is Voltage Source Converter (VSC), so active and reactive power can be controlled independently. The VSCs connected to the wind farms (wind farm rectifiers) inject the wind power to the HVDC grid. In normal operation, the wind farm rectifiers absorb all the power produced from wind farms and inject it into the DC grid. They also provide the needed reactive power to maintain the $\mathrm{AC}$ wind farm voltage. The power in the $\mathrm{DC}$ network is delivered to the AC grid through grid connected VSC, that are in charge of HVDC grid voltage control and which deliver reactive power support to the AC grid when needed. The AC grid is constituted by AC links that enable the electrical power transmission to the consumption nodes. The active and reactive power demands in the $\mathrm{AC}$ nodes and the wind farm's generation are an input for the tool. The electrical characteristics of the DC and AC grids and the converter loss parameters are also known data. The tool determines the active and reactive power produced from generators and converters and the power flowing through branches that minimize the specified objective function while accomplishing the electrical system constraints.

It is worth mentioning that the $\mathrm{OPF} \mathrm{AC} / \mathrm{DC}$ leading to the following formulation was previously

validated $[14,20]$. It was first implemented through MATLAB ${ }^{\circledR}$ Optimization toolbox and it was benchmarked with the OPF tool from [21], implemented in MATPOWER ${ }^{\circledR}$. Both tools led to the same results for the system analysed (5 AC 3 DC) when minimising losses and when minimising the deviation from a preset voltage profile [20]. On the other hand, the OPF AC/DC tool was also 
implemented in GAMS ${ }^{\circledR}$ [14], leading to the same results that MATLAB ${ }^{\circledR}$ Optimization toolbox for small and large power systems. However, as GAMS ${ }^{\circledR}$ was proved to be far more efficient than MATLAB ${ }^{\circledR}$ from a computational point of view, it has been chosen for implementing the expanded OPF executed by the central controller.

[Figure 1 about here.]

\subsection{Notation}

All the variables and parameters required for the mathematical formulation of the problem are detailed below.

- $\mathbf{G}_{\mathbf{D C}}$ conductance matrix of the DC grid

- $\mathbf{G}_{\mathbf{A C}}$ conductance matrix of the AC grid

- $\mathbf{B}_{\mathbf{A C}}$ susceptance matrix of the AC grid

- $i \in(1, n), n$ is the number of VSC converters

- $j \in(1, p), p$ is the number of AC nodes

- $s \in(1, r), r$ is the number of grid side VSCs

- $\mathbf{I}=\left[I_{1} \cdots I_{n}\right]^{T}$ vector of DC currents

- $\mathbf{E}=\left[E_{1} \cdots E_{n}\right]^{T}$ vector of DC voltages

- $\mathbf{E}^{*}=\left[E_{1}^{*} \cdots E_{r}^{*}\right]^{T}$ vector of DC droop offset voltages for grid side VSCs

- $\mathbf{V}=\left[V_{1} \cdots V_{p}\right]^{T}$ vector of AC voltage magnitude

- $\boldsymbol{\delta}=\left[\delta_{1} \cdots \delta_{p}\right]^{T}$ vector of AC voltage angles

- $E_{i}$ and $I_{i}$ are, respectively, the DC voltage and the current entering in node $i$.

- $V_{j}$ and $\delta_{j}$ are, respectively, the AC voltage magnitude and angle of voltage phasor in node $j$

- $\mathbf{P}_{\mathbf{D C}}=\left[P_{D C_{1}} \cdots P_{D C_{n}}\right]^{T}$ is the power entering the DC system through the converters 
- $\mathbf{P}=\left[P_{1} \cdots P_{m+p}\right]^{T}$ is the active power in each AC node

- $\mathbf{P}_{\mathbf{g}}=\left[P_{g_{1}} \cdots P_{g_{p}}\right]^{T}$ is the active power generated in each AC node

- $\mathbf{P}_{\mathbf{d}}=\left[P_{d_{1}} \cdots P_{d_{p}}\right]^{T}$ is the active power demanded in each AC node

- $\mathbf{Q}_{\mathbf{v s c}}=\left[Q_{1} \cdots Q_{n}\right]^{T}$ is the reactive power injection/absorption by each converter

- $\mathbf{Q}_{\mathbf{g}}=\left[Q_{g_{1}} \cdots Q_{g_{p}}\right]^{T}$ is the reactive power generated in each AC node

- $\mathbf{Q}_{\mathbf{d}}=\left[Q_{d_{1}} \cdots Q_{d_{p}}\right]^{T}$ is the reactive power demanded in each AC node

- $\mathbf{S}_{\mathbf{v s c}}=\left[S_{1} \cdots S_{n}\right]^{T}$ is the power rating of each converter

\subsection{Inputs}

The input data required for the optimization problem is detailed below:

- Conductance matrix of the DC grid: $\mathbf{G}_{\mathbf{D C}}$

- Conductance and susceptance matrix of the $\mathrm{AC}$ grid: $\mathbf{G}_{\mathbf{A C}}$ and $\mathbf{B}_{\mathbf{A C}}$

- Active and reactive power demand in the $\mathrm{AC}$ grid nodes: $\mathbf{P}_{\mathbf{d}}$ and $\mathbf{Q}_{\mathbf{d}}$

- Droop constant vector for the grid side VSC: $k_{d r o o p}$

- Converter loss parameters

\subsection{Outputs}

The optimization algorithm determines the voltages in all the nodes and the power flowing in the different branches that minimize a user defined objective function and ensure all the equality and inequality constraints compliance. The output vector of the algorithm, $\mathbf{x}$, contains the following information:

$$
\mathbf{x}=\left[E, I, V, \delta, P, Q, E^{*}\right]^{T}
$$




\subsection{Mathematical formulation}

The mathematical problem that when solved, knowing the inputs detailed in Section 2.2, leads to the solution output presented in Section 2.3, is classified as non-linear constrained optimization $[22,23]$. Let $n, l$, and $m$ be positive integers. Let $\mathrm{X}$ be a subset of $\Re^{n}$. Let $f, g_{u}$, and $h_{v}$ be real-valued functions on $\mathrm{X}$ for each $u$ in $\{1, \ldots, l\}$ and each $v$ in $\{1, \ldots, m\}$, with at least one of $f$, $g_{u}$, and $h_{v}$ being non-linear. The generic mathematical formulation of the optimization problem is as follows:

$$
\min f(\mathbf{x})
$$

subject to

$$
\begin{array}{r}
g_{u}(\mathbf{x})=0 \forall u \in\{1, \ldots, l\} \\
h_{v}(\mathbf{x}) \leq 0 \quad \forall v \in\{1, \ldots, m\}
\end{array}
$$

where $\mathbf{x} \in \mathrm{X}$. The problem is formulated designing the objective function as $f(\mathbf{x})$ (detailed in Section 2.5), which is dependent on the variables defined in (1) and subject to the constraints $g_{u}$ and $h_{v}$ (expressed by Equations (5)-(18)) [14]. These equations define DC and AC power system equations (see Equations (5)-(8) and (19)-(20)), the voltage droop law (Equation (21)) the limits of voltages and currents in the DC nodes (Equations (9)-(11)), the limits of voltages and powers in AC nodes (Equations (13)-(17)) and the power flow limitation in DC branches and in AC branches (Equation (12) and (18), respectively). These equations are detailed in [14, 24]. 


$$
\begin{array}{r}
\mathbf{I}=\mathbf{G}_{\mathbf{D C}} \mathbf{E} \\
P_{D C_{i}}=E_{i} I_{i} \\
P_{D C_{i}}-P_{\text {lossvsc }_{i}}=P_{j}+P_{g_{j}}-P_{d_{j}} \\
Q_{j}=Q_{v s c_{j}}+Q_{g_{j}}-Q_{d_{j}} \\
E_{i}^{\text {min }} \leq E_{i} \leq E_{i}^{\text {max }} \\
E_{s}^{\text {min* }} \leq E_{s}^{*} \leq E_{s}^{\text {max }} \\
I_{i}^{\text {min }} \leq I_{i} \leq I_{i}^{\text {max }} \\
P_{k l}^{\text {min }} \leq G_{k l}\left(E_{k}-E_{l}\right) E_{k} \leq P_{k l}^{\text {max }} \\
V_{j}^{\text {min }} \leq V_{j} \leq V_{j}^{\text {max }} \\
P_{j}^{\text {min }} \leq P_{j} \leq P_{j}^{\text {max }} \\
Q_{j}^{\text {min }} \leq Q_{j} \leq Q_{j}^{\text {max }} \\
\delta_{j}^{\text {min }} \leq \delta_{j} \leq \delta_{j}^{\text {max }} \\
S_{v s c_{i}}^{\text {min }} \leq S_{v s c} \leq S_{v s c_{i}}^{\text {max }} \\
S_{k l}^{\text {min }} \leq S_{k l} \leq S_{k l}^{\text {max }}
\end{array}
$$

being

$$
\begin{aligned}
& P_{j}=V_{j} \sum_{k=1}^{p} V_{k}\left(G_{A C j k} \cos \delta_{j k}+B_{A C j k} \sin \delta_{j k}\right) \\
& Q_{j}=V_{j} \sum_{k=1}^{p} V_{k}\left(G_{A C j k} \sin \delta_{j k}-B_{A C j k} \cos \delta_{j k}\right)
\end{aligned}
$$

Additionally, the DC current injected by the grid side VSC $s$ satisfies droop voltage control:

$$
I_{D C_{s}}^{*}=k_{\text {droop }_{s}}\left(E_{s}-E_{s}^{*}\right)
$$

The AC links are modelled according to the $\pi$ equivalent diagram. The active power exchange on the AC and DC side of the converter differ on losses. So, the AC power can be defined as a function of the DC power and converter losses, modelled according to a second order polynomial, as in $[18]$. 
Taking into account the non-linearity of the problem and its size, the solver used for determining the solution is CONOPT $[25,26]$, designed for large and sparse models. It uses a fast method for determining a first feasible solution, specially interesting for models with few degrees of freedom. It removes recursive equations and variables from the model and is specially suitable for models with approximately the same number of constraints.

\subsection{Objective functions}

The objective function presented in (2.5) can be chosen among several functions which are of interest in terms of operation or planning of the system. Two of them are shown below. Minimum power losses (to be applied in systems or subsystems where the total transmission losses want to be minimized):

$$
\min f(x)=\sum_{j=1}^{p}\left(P_{g_{j}}-P_{d_{j}}\right)
$$

Minimum generation costs (to be applied when the cost function of generation of the different generating units is known and depends on the power delivered; the production of units with minimum generating cost will be prioritized):

$$
\min f(x)=\sum_{j=1}^{n_{g}} C_{j}\left(P_{g_{j}}\right)
$$

where $n_{g}$ represents the number of generators.

\section{HVDC scaled experimental platform}

The tool presented in Section 2 is tested experimentally in an HVDC scaled platform, emulating a 4 terminal DC system where two converters inject the power produced by two wind farms into the DC grid and two converters transmit this power to the AC grid. The AC grid is not physically built in the laboratory, but simulated through MATLAB simulink ${ }^{\circledR}$ instead. The system topology used for this study is a $4 \mathrm{DC}$ bus and $6 \mathrm{AC}$ bus network, based on the test system defined by CIGRE in [27] and sketched in Fig. 3.

[Figure 2 about here.] 
The scaled experimental platform available at the laboratory is depicted in Figure 2. Its design, operation and control are discussed in [28]. Each Wind farm injection is emulated through a squirrel cage induction motor mechanically coupled to a squirrel cage induction generator connected to a VSC. The aerodynamic behaviour of the wind turbines is emulated via a PC, connected to the experimental platform through a National Instruments SCADA, based on LABVIEW, in charge of supervising the status of the different variables and allowing the sending of wind power references by means of a DAQ (Data Acquisition). The VSC converters used are two-level converters based on IGBTs. They consist of three boards: the power board, the drivers board and the control board (based on a Texas instrument Digital Signal Processor (DSP) TMS320F2808). This DSP interacts with the IGBTs by means of a driver board that provides the necessary gate-excitation signals. The electrical characteristics of the converters, generators and cables of the DC system of the experimental platform are specified in Section 6. An OPF algorithm is solved periodically in a PC to ensure minimum losses in the system. The OPF is solved using $\mathrm{GAMS}^{\circledR}$, an optimization dedicated software. To do so, the admittance matrices for the DC and AC grids are known $\left(G_{D C}\right.$ and $Y_{A C}$ ), as well as the DC power injected by wind farms into the DC grid. The demands of all the nodes are also input data. The outputs of the OPF algorithm are the voltage references for the droop controls implemented in each grid side converter and their reactive power reference, as well as the active and reactive power setpoints for the AC generators (see Fig. 3). The diagram of the process for operating the system implemented in the laboratory platform is depicted in Fig. 4. The computation time for solving the optimization is very dependent on the number of nodes of the system. Several network sizes were analysed in [14]. The optimization problem expressed in [14] is the same that the one presented in this study, without considering the droop control equation of each converter node. From [14], it is deduced that the complexity of the optimization problem is $O\left(n^{2}\right)$. Taking into account that the system emulated at the laboratory consists of 4 DC nodes and 6 AC nodes, the computation time for solving the optimization in GAMS ${ }^{\circledR}$ does not exceed $0.1 \mathrm{~s}$, independently if the solver used is CONOPT or IPOPT, [25] as shown in [14]. The algorithm period execution has been chosen taking into account the time required for sending the signals, the computation time of the OPF, the time needed for receiving the output signals of the $\mathrm{OPF}$ and the time for applying these signals locally. Thus, including the communication delay, $5 \mathrm{~s}$ 
is a very conservative value for executing the algorithm. For larger systems, the execution period would be increased, if needed.

[Figure 3 about here.]

The output signals are sent from the PC to the DSPs of the grid side converters through CAN (Controller Area Network) communications. MATLAB ${ }^{\circledR}$ has special toolboxes to communicate with CAN, so MATLAB ${ }^{\circledR}$ is used to exchange signals between the experimental platform and the OPF algorithm executed periodically through GAMS ${ }^{\circledR}$. From an implementation point of view, CAN is used in the scaled experimental platform, not only for allowing an easy connection between the optimization algorithm and the DSP of each converter, but also for being a robust deterministic standard: the maximum time to deliver the information is known. Even if the wind farm converter terminals have different time delays, the execution time of the algorithm does not compromise the performance of the system, as it is not executed until all the input signals are received. Although it is not a realistic situation, it may happen that some grid side converters apply the new voltage reference a few ms before than others, but this does not affect the system performance (it can be seen in Fig. 6(c) that voltage droop has a slow response). On the other hand, as it is known, and stated in [29], CAN 2.0b standard does not define the physical layer. In a real system, the physical layer used to transmit the information could be fibre optics, with delays of nanoseconds, so the communication delay effect is not significant taking into consideration the execution time of the algorithm.

[Figure 4 about here.]

\section{Case studies}

\subsection{Normal operation}

The operation scenarios analysed are wind speed variation (case study 1), loss of communications (case study 2) and change in the AC demand (case study 3). Next sections show the comparison of experimental measurements and the results obtained from dynamic simulations with MATLAB ${ }^{\circledR}$. The losses in the DC grid and the losses of the converters are computed and 
analysed. The wind power injection into the DC grid for each case study is depicted in Figure 5. For all these scenarios the reactive power demand in each node is considered to be $10 \%$ of the active power demand. For the two first scenarios the demand is supposed to be constant. The experimental measurements (plotted in transparent grey) have been filtered calculating their mean value each $1 \mathrm{~s}$, so as to remove the signals noise. In all the scenarios analysed, HVDC grid losses are lower than converter losses (Fig. 9(a)-9(b)-9(c)). This particular conclusion is not representative of the behaviour of real HVDC-HVAC systems. It must be taken into account that, although the algorithm is designed for HVDC-HVAC networks, the validation has been performed in a scaled experimental platform, designed for low voltage operation and with a few amperes currents in branches. Consequently, grid losses are in general very low and, in particular converters present larger losses than in DC branches.

[Figure 5 about here.]

\subsubsection{Wind speed change}

The first operation scenario corresponds to wind speed step changes in both wind farms. The demand in the $\mathrm{AC}$ nodes is set null in all the nodes except in nodes 3 and 6 (see Figure 3), where it is 0.1 p.u. (1000 W) for active power and 0.01 p.u (100 Var) for reactive power. This variation causes changes in the power injected into the DC grid. As depicted in Figure 5(a) at time $17 \mathrm{~s}$, Wind farm 2 (see Figure 3) increases the power produced from $1000 \mathrm{~W}$ to $1850 \mathrm{~W}$. Then, at time $47 \mathrm{~s}$, it decreases the generation to $700 \mathrm{~W}$, and finally it increases again to $1550 \mathrm{~W}$ at time $80 \mathrm{~s}$. On the other hand, Wind farm 1, decreases its power injection from $380 \mathrm{~W}$ until $150 \mathrm{~W}$ at time $32 \mathrm{~s}$ and then recovers the $380 \mathrm{~W}$ at time $60 \mathrm{~s}$. The power variation from wind farms leads to voltage changes (see Fig. 6(c)-6(d)) and therefore, to a branches current redistribution (see Fig. $6(\mathrm{a})-6(\mathrm{~b}))$.

[Figure 6 about here.]

As the power injected into the DC grid increases, the OPF drops the DC voltages of the grid so as to keep the maximum power injection: voltages are stable and losses in both DC and AC systems are minimum. Comparing simulation and experimental results, the DC grid voltages present a similar time evolution. The peaks on voltages appear due to the fact that there is a 
change in the power injected from the wind farms but the central controller has not yet seen this variation. As a consequence of the different operating points on the DC grid as time evolves, losses on VSCs and in the HVDC grid will also change, as depicted in Fig. 6(e)-6(f).

\subsubsection{Communication loss}

In order to guarantee optimal operation, communications are needed so that information can be exchanged between the upper level control that executes the OPF and the voltage droop control. A scenario where an eventual loss of communications occurs is here analysed, showing that the system can still operate without compromising its stability even if communications are lost thanks to the distributed voltage control (based on droop), which does not require communications. To show this, an eventual loss of communications is simulated from time $10 \mathrm{~s}$ until time $87 \mathrm{~s}$ (a blue band clarifies the time range when communications are not available). The demand in the AC nodes is set null in all the nodes except in nodes 3 and 6 (see Figure 3), where it is 0.1 p.u. (950 W) for active power and 0.01 p.u (100 Var) for reactive power. In this case, as depicted in Fig. 5(b) the power injection from wind farms changes at time $8 \mathrm{~s}$ for Wind farm 2, increasing from $400 \mathrm{~W}$ to $950 \mathrm{~W}$ and decreasing again to $400 \mathrm{~W}$ at time $68 \mathrm{~s}$. Wind farm 1 increases its generation at time $28 \mathrm{~s}$ from 350 to $450 \mathrm{~W}$ and reduces it from 450 until $250 \mathrm{~W}$ at time $59 \mathrm{~s}$.

[Figure 7 about here.]

However, the OPF algorithm is not able to adapt the voltage references according to all these wind power changes, because communications between the wind farm VSCs and the central controller are lost at time $10 \mathrm{~s}$.

Under these circumstances, the operation of the whole AC/DC system inside its limits (avoiding instabilities) is prioritised over it optimal operation. The strategy consists in keeping the last voltage reference sent to the grid side VSCs before communications were lost until they are recovered. They are not optimal anymore, because they do not correspond to the actual wind power generation (which is unknown for the central controller during the time range communications are not available). However, stable operation is guaranteed possible thanks to the distributed control of the grid side VSCs. Once communications are recovered, the actual wind farm generation is again available for the central controller and the optimal references can again be computed. 
In Fig. 7(c)-7(d) it can be seen that the voltage reference for droop control is kept since communications are lost until they are recovered. Comparing simulation and experimental results, the voltages of the DC grid present a few $\mathrm{V}$ difference, but their time evolution very close. In this situation minimum losses can not be ensured, but stable operation is guaranteed. The evolution of the DC branches currents is depicted in Fig. 7(a)-7(b). It can be noted that the communication loss in the experimental results is a few seconds shifted. The reason is that in the scaled experimental platform, the loss of communications in signals affecting DC voltage references and reactive powers references could not be done at the same time instant (as two different parameters had to be changed manually) while it was in operation. During the time range that communications are not available, losses in the grid and in the VSCs increase (see Fig. 7(e)-7(f)), as optimal operation can not be guaranteed. For the same power injection, when the OPF signals are applied, the losses are minimized (see how losses between time range 70-87 s are reduced after communications recover, from instant $87 \mathrm{~s}$ on, when the OPF signals can be sent and, therefore, applied). The losses reduction is not very significant in the case studied, for being a low voltage platform where only a few amperes are circulating. However, for real HVDC-HVAC systems, this loss minimization would be considerable.

\subsubsection{Demand variation}

The third operation scenario corresponds to a demand change on the AC system. The demand in the AC nodes is set null in all the nodes except in node 6 (see Figure 3), where it is 0.5 p.u. $(500 \mathrm{~W})$ for active power and 0.005 p.u. (50 Var) for reactive power. At time $27 \mathrm{~s}$ the demand in this node decreases to 0.1 p.u. (100 W) for active power and 0.001 p.u. (10 Var) for reactive power. As depicted in Figure 5(c), the wind power in both Wind farms remains constant: it is kept at $250 \mathrm{~W}$ for Wind farm 1 and at $1000 \mathrm{~W}$ for Wind farm 2.

[Figure 8 about here.]

As a consequence of the load decrease, although the power injection from wind farms does not change but the $\mathrm{AC}$ demand does, the DC power flows will change to ensure minimum losses for the new operating point. This is due to the fact that the OPF solves the system using a unified approach and not sequential. If a sequential strategy was used, this means solving the AC system 
and DC system separately and using the outputs of one as inputs for the other, the DC power flows would not have probably changed. So, in this case, the OPF changes the droop references to ensure minimum losses, as depicted in Figure 8(c)-8(d). Comparing simulation and experimental results, the voltages of the DC grid present a few $\mathrm{V}$ difference, but their time evolution coincides.

The current branch redistribution is presented in Fig. 8(a)-8(b). The corresponding losses are represented in Fig. 8(e)-8(f).

[Figure 9 about here.]

\subsection{Operation under contingency}

The response of the system operated through the OPF algorithm in case of contingency is analysed in this section through dynamic simulations. A scenario considers the disconnection of a VSC and another scenario considers the disconnection of a DC cable. In both cases, the wind power injections correspond to the represented in Figure 10 [30], which take into account wind speed variability.

[Figure 10 about here.]

\subsubsection{VSC disconnection}

The VSC connected to Wind farm 2 is disconnected at time instant $23 \mathrm{~s}$, then the wind power being injected into the DC grid by this wind farm can no longer be delivered to the DC system. Optimal operation is still guaranteed as the voltage references sent by the OPF to the grid side converters are adapted to the new power injection from wind farms, which is globally lower than before the disconnection occurs. So the voltage references sent by the central controller to the grid side converters are lower than those before the contingency and, therefore, the voltage levels in the DC grid decrease (see Fig. 11(b)). As the currents in DC branches also decrease (Fig. 11(a)), the HVDC grid losses are reduced (Fig. 11(c)). All converter losses also diminish (Fig. 11(d)), being null for the converter disconnected after the contingency.

[Figure 11 about here.] 


\subsubsection{Cable disconnection}

In case a cable is disconnected, the system can still operate optimally thanks to the grid reconfiguration detection. The central controller can detect (with some delay) the cable loss and recalculates the admittance matrix of the system. This way, the central controller can calculate the appropriate references for the resulting power system after the contingency. To show this, the disconnection of the cable linking the two wind farms is simulated, at time instant 18 s. The voltage references for the grid side VSCs of the last OPF are kept until the next execution. As the algorithm is executed every $5 \mathrm{~s}$, the central controller has enough time to detect the cable disconnection and determine the new admittance matrix. Then, the new references sent to the grid VSCs correspond to the optimal ones for the new grid configuration and actual wind power injection. The DC grid voltages increase after the cable disconnection (see Fig. 12(b)). The current flowing through the faulty cable becomes null after the disconnection (Fig. 12(a)) and the power will be only transmitted through the safe cables. As the currents before and after the DC cable disconnection do not present large differences, the HVDC grid losses (Fig. 12(c)) and converter losses (Fig. 12(d)) are also quite close.

[Figure 12 about here.]

\subsection{Wind power measurements uncertainty impact}

In the before presented case studies, wind power generation measurements did not present uncertainty. However, the power measurements at each wind power plant could present some error. In this case, the wind power values communicated to the central controller would be different than the real wind power being produced. The effect of measurements uncertainty in the OPF output signals is here analysed using realistic wind profiles [30]. The real values of wind power have been represented in Fig. 13 with continuous lines, while the measurements with error (which varies in time) have been represented with dashed lines. Two scenarios have been simulated: the ideal one in which the measurement and the real value of wind power generation is the same (no uncertainty in measurements) and a scenario in which the measurement presents some deviation respect to the real value (considering measurements uncertainty). The results for the two scenarios are plotted in Fig. 14. The dashed lines correspond to the results obtained when there is uncertainty in wind power measurements and the continuous lines correspond to the results when there is null 
uncertainty. In particular, Fig. 14(a) shows the DC branch currents distribution, Fig. 14(b) shows DC bus voltages and Fig. 14(c) and 14(d) the DC grid losses and grid side VSC converter losses, respectively. As the wind power generation being input to the central controller is not exactly the real one, the voltage references, calculated after solving the OPF, and sent to the VSC, present some differences respect to the base case (in which there is null uncertainty), but not a very significant deviation according to the simulations.

[Figure 13 about here.]

[Figure 14 about here.]

\section{Conclusions}

A methodology to operate HVDC-HVAC networks while guaranteeing optimal operation has been proposed. The approach combines an OPF algorithm executed by a central controller with a distributed control, based on voltage droop acting in the grid side converters. The algorithm presented has been applied to ensure minimum losses in a particular HVDC-HVAC network, under different scenarios: wind power variation, loss of communications, demand changes and contingencies. Under wind power variation and under demand changes, the algorithm guarantees stable operation and minimum losses. In case communications are lost, optimal transmission can not be assured while they are unavailable and the system keeps its stable operation thanks to the distributed voltage control. All the previous results have been validated through experiments in a scaled experimental platform. It has also been shown through dynamic simulations that the optimal operation can still be guaranteed even if a DC cable is disconnected (once detected by the central controller) and in case a VSC is disconnected.

\section{Appendix}

[Table 1 about here.]

[Table 2 about here.] 


\section{Acknowledgements}

This work was supported by the Ministerio de Ciencia e Innovación under the projects ENE201347296 and ENE2015-67048-C4-1-R.

\section{References}

[1] Ivan Pineda and Kristian Ruby. Aiming High. Rewarding ambition in Wind Energy. EWEA, European Wind Energy Association, 2015.

[2] CIGRÉ Working Group B-4.52. HVDC grid feasibility study. International Council for Large Electric Systems (CIGRÉ), Technical Brochure 533, 2013.

[3] Til Kristian Vrana, Jef Beerten, Ronnie Belmans, and Olav Bjarte Fosso. A classification of dc node voltage control methods for HVDC grids. Electric Power Systems Research, 103:137 $-144,2013$.

[4] R. Teixeira Pinto, P. Bauer, S. F. Rodrigues, E. J. Wiggelinkhuizen, J. Pierik, and B. Ferreira. A novel distributed direct-voltage control strategy for grid integration of offshore wind energy systems through mtdc network. IEEE Transactions on Industrial Electronics, 60(6):24292441, June 2013.

[5] E. Prieto-Araujo, F. D. Bianchi, A. Junyent-Ferre, and O. Gomis-Bellmunt. Methodology for droop control dynamic analysis of multi-terminal vsc-hvdc grids for offshore wind farms. IEEE Transactions on Power Delivery, 26(4):2476-2485, 2011.

[6] M. Aragüés-Peñalba, A. Egea-Àlvarez, S. Galceran Arellano, and O. Gomis-Bellmunt. Droop control for loss minimization in hvdc multi-terminal transmission systems for large offshore wind farms. Electric Power Systems Research, 112:48 - 55, 2014.

[7] Eduardo Jiménez, Miguel Jiménez Carrizosa, Abdelkrim Benchaib, Gilney Damm, and Françoise Lamnabhi-Lagarrigue. A new generalized power flow method for multi connected DC grids. International Journal of Electrical Power and Energy Systems, 74:329 - 337, 2016. 
[8] A bi-objective DC-optimal power flow model using linear relaxation-based second order cone programming and its pareto frontier. International Journal of Electrical Power and Energy Systems, 88:13 - 20, 2017.

[9] Miguel Jiménez Carrizosa, Fernando Dorado Navas, Gilney Damm, and Françoise LamnabhiLagarrigue. Optimal power flow in multi-terminal HVDC grids with offshore wind farms and storage devices. International Journal of Electrical Power and Energy Systems, 65:291 - 298, 2015.

[10] Florin Capitanescu. Critical review of recent advances and further developments needed in ac optimal power flow. Electric Power Systems Research, 136:57 - 68, 2016.

[11] Jia Cao, Zheng Yan, Jianhua Li, and Lu Cao. Impact of hvdc line on the convergence property of ac/dc power flow calculation. International Journal of Electrical Power and Energy Systems, $83: 140-148,2016$.

[12] R. Eriksson, J. Beerten, M. Ghandhari, and R. Belmans. Optimizing dc voltage droop settings for ac/dc system interactions. IEEE Transactions on Power Delivery, 29(1):362-369, Feb 2014.

[13] E. Iggland, R. Wiget, S. Chatzivasileiadis, and G. Anderson. Multi-area dc-opf for hvac and hvdc grids. IEEE Transactions on Power Systems, 30(5):2450-2459, Sept 2015.

[14] M. Aragüés-Peñalba, A. Egea, S. Galceran-Arellano, and O. Gomis-Bellmunt. Optimal power flow tool for mixed HVAC and HVDC high voltage direct current systems for grid integration of large wind power plants. IET renewable power generation, 9(8), 2015.

[15] M. Aragüés Peñalba, J. Rimez, J. Beerten, D. V. Hertem, and O. Gomis-Bellmunt. Secure and optimal operation of hybrid ac/dc grids with large penetration of offshore wind. In 11th IET International Conference on $A C$ and DC Power Transmission, pages 1-9, Feb 2015.

[16] J. Cao, W. Du, and H. F. Wang. An improved corrective security constrained opf for meshed ac/dc grids with multi-terminal vsc-hvdc. IEEE Transactions on Power Systems, 31(1):485495, Jan 2016. 
[17] R. Teixeira Pinto, M. Aragüés-Peñalba, O. Gomis-Bellmunt, and A. Sumper. Optimal operation of dc networks to support power system outage management. IEEE Transactions on Smart Grid, 7(6):2953-2961, Nov 2016.

[18] J. Beerten, S. Cole, and R. Belmans. Generalized steady-state VSC MTDC model for sequential AC/DC power flow algorithms. Power Systems, IEEE Transactions on, 27(2):821-829, 2012.

[19] M. Baradar and M. Ghandhari. A multi-option unified power flow approach for hybrid AC/DC grids incorporating multi-terminal vsc-hvdc. IEEE Transactions on Power Systems, 28(3):2376-2383, Aug 2013.

[20] M Aragüés-Peñalba, J. Beerten, J. Rimez, D. Van Hertem, and O. Gomis-Bellmunt. Optimal power flow tool for hybrid dc/ac systems. In IET AC DC, 2015.

[21] J. Rimez and R. Belmans. A combined AC/DC Optimal Power Flow Algorithm for meshed $\mathrm{AC}$ and DC Networks linked by VSC Converters. International Transactions on Electrical Energy Systems, Wiley, 2014.

[22] Reiner Horst and Tuy Hoang. Global Optimization: deterministic approaches. Springer, third edition, 1996.

[23] Stephen P. Boyd and Lieven Vandenberghe. Convex Optimization. Cambdridge Univeristy Press, first edition, 2004.

[24] P. Kundur. Power System Stability and Control. Mc.Graw Hill, Inc, 1993.

[25] GAMS. The solver manuals. GAMS Development Corporation, Washington, DC, USA, 2015.

[26] Neculai Andrei. Nonlinear Optimization Applications Using the GAMS Technology. Springer Publishing Company, Incorporated, 2013.

[27] CIGRÉ Working Groups B4-58 and B4-57. The CIGRÉ B4 DC grid test system. International Council for Large Electric Systems (CIGRÉ), 2013. 
[28] A. Egea-Alvarez, F. Bianchi, A. Junyent-Ferre, G. Gross, and O. Gomis-Bellmunt. Voltage control of multiterminal vsc-hvdc transmission systems for offshore wind power plants: Design and implementation in a scaled platform. Industrial Electronics, IEEE Transactions on, 60(6):2381-2391, June 2013.

[29] Marco Di Natale, Haibo Zeng, Paolo Giusto, and Arkadeb Ghosal. The CAN 2.0b Standard, pages 1-24. Springer New York, New York, NY, 2012.

[30] Sergio Martin-Martínez, Antonio Vigueras-Rodríguez, Emilio Gómez-Lázaro, Angel MolinaGarcía, Eduard Muljadi, and Michael Milligan. Wind power variability and singular events. In Rupp Carriveau, editor, Advances in Wind Power, chapter 12. InTech, Rijeka, 2012. 


\section{List of Figures}

1 HVDC-HVAC network for integrating offshore wind power . . . . . . . . . . . . . 24

24 DC scaled experimental platform [28] . . . . . . . . . . . . . . . . . . . . . . . . . . . . . . . 25

3 System monitoring and signals exchange . . . . . . . . . . . . . . . . . 26

4 Algorithm sequence implemented in HVDC scaled experimental platform . . . . . . 27

5 Power injection from wind farms for each case study . . . . . . . . . . . . . . . . 28

6 Case study 1: wind speed changes. Simulation results on left plots and experimental results on right plots . . . . . . . . . . . . . . . . . . . . . . 29

7 Case study 2: loss of communications. Simulation results on left plots and experimental results on right plots . . . . . . . . . . . . . . . . 30

8 Case study 3: demand variation. Simulation results on left plots and experimental results on right plots . . . . . . . . . . . . . . . . . . . 31

9 Converters losses for each case study . . . . . . . . . . . . . . . . . . . . . 32

10 Wind power profiles . . . . . . . . . . . . . . . . . . . . 33

11 VSC disconnection . . . . . . . . . . . . . . . . . . . . . . . 34

12 Cable disconnection . . . . . . . . . . . . . . . . . . . . . 35

13 Wind power profiles . . . . . . . . . . . . . . . . . 36

14 Wind power variability and uncertainty effect . . . . . . . . . . . . . 37 


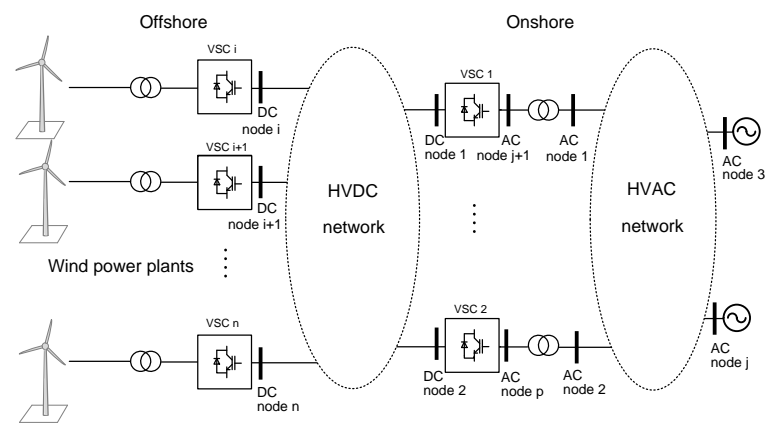

Figure 1: HVDC-HVAC network for integrating offshore wind power 


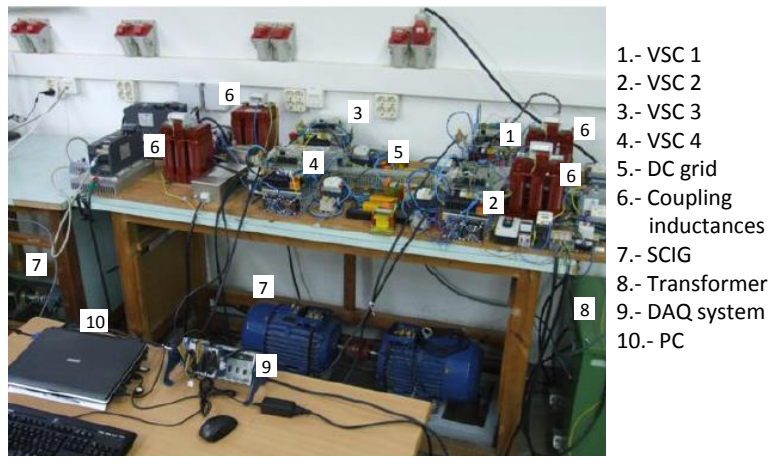

Figure 2: 4 DC scaled experimental platform [28] 


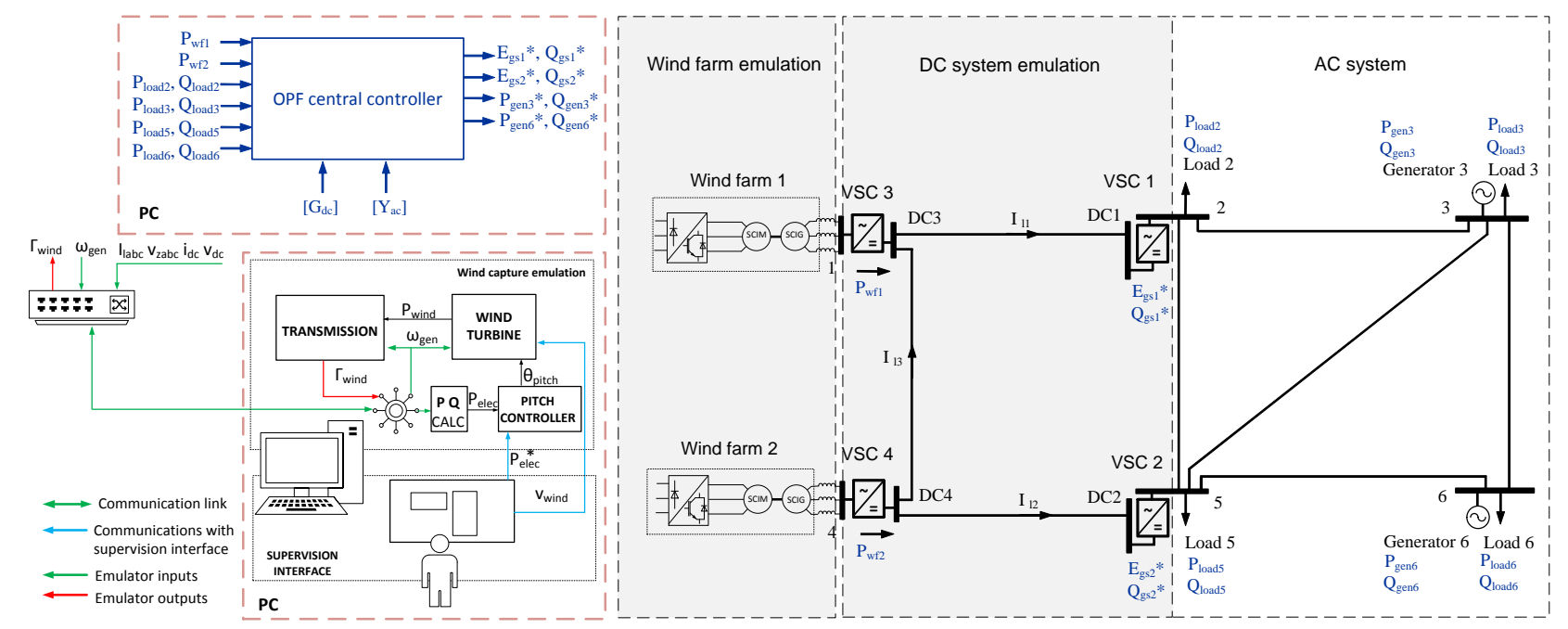

Figure 3: System monitoring and signals exchange 


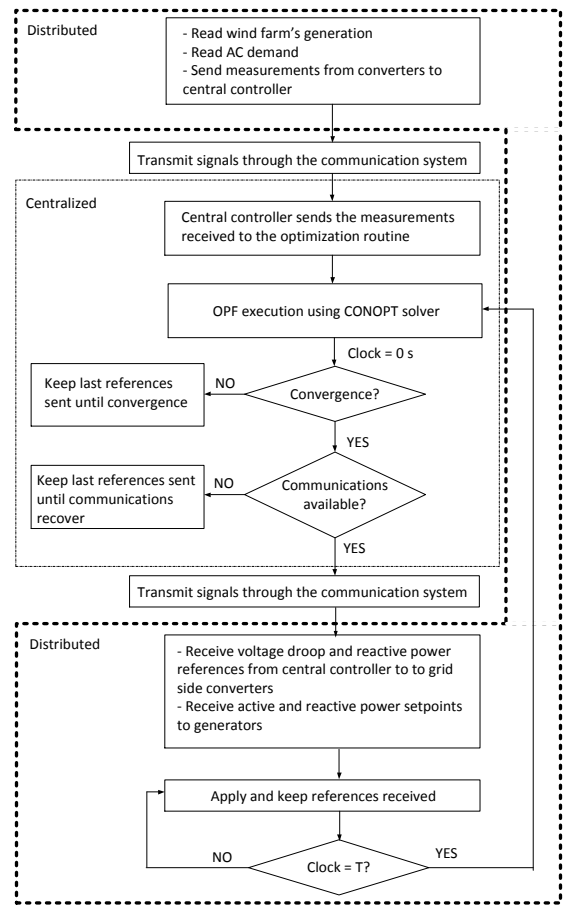

Figure 4: Algorithm sequence implemented in HVDC scaled experimental platform 


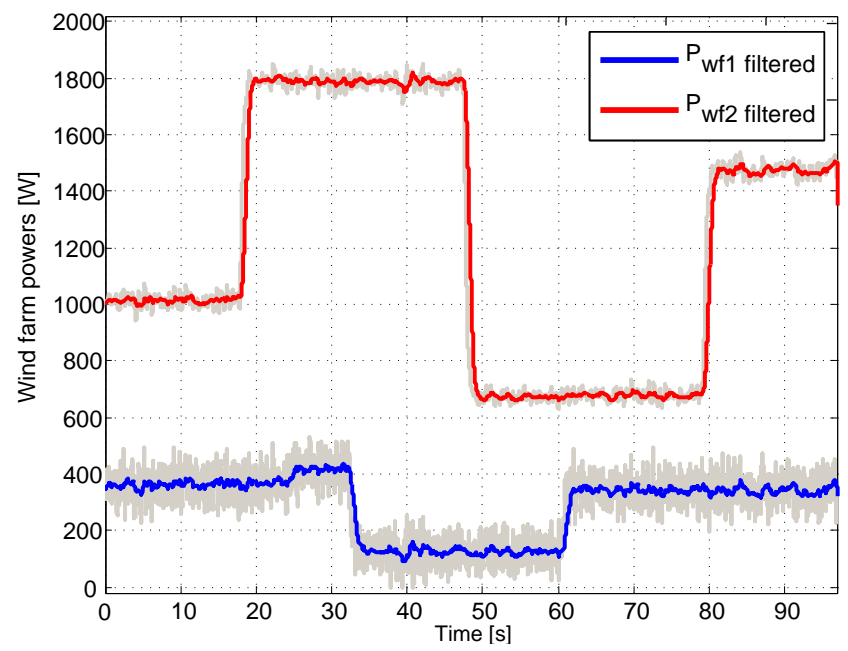

(a) Case study 1: wind speed changes

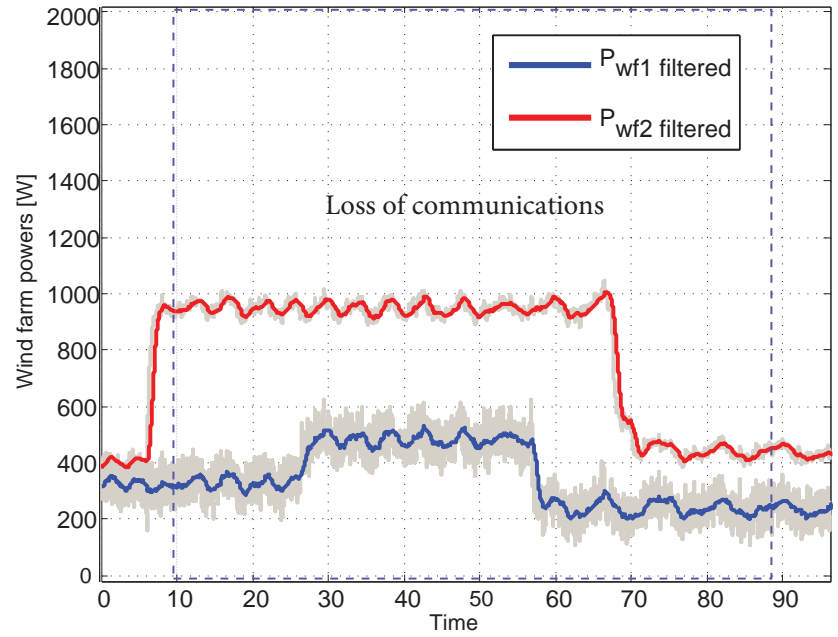

(b) Case study 2: loss of communications

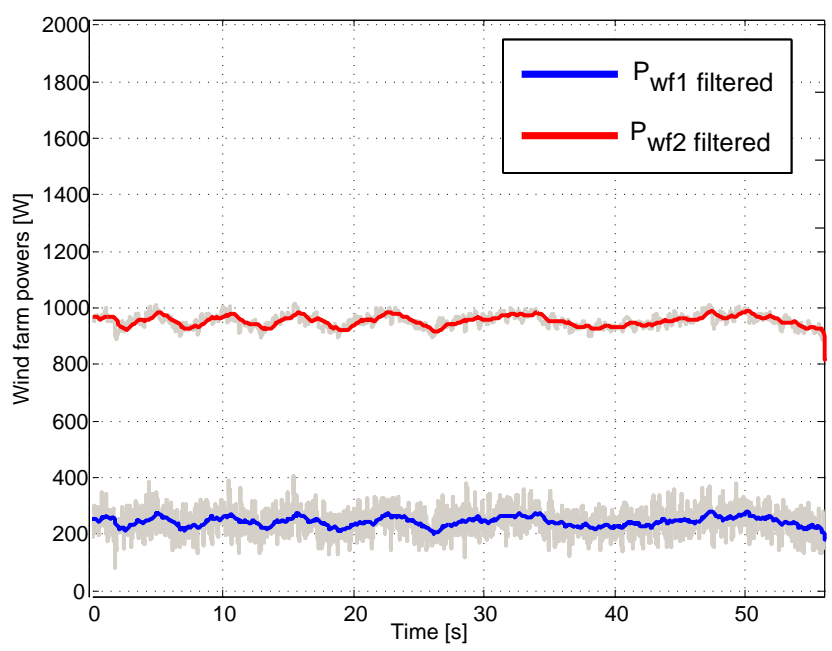

(c) Case study 3: demand variation

Figure 5: Power injection from wind farms for each case study 


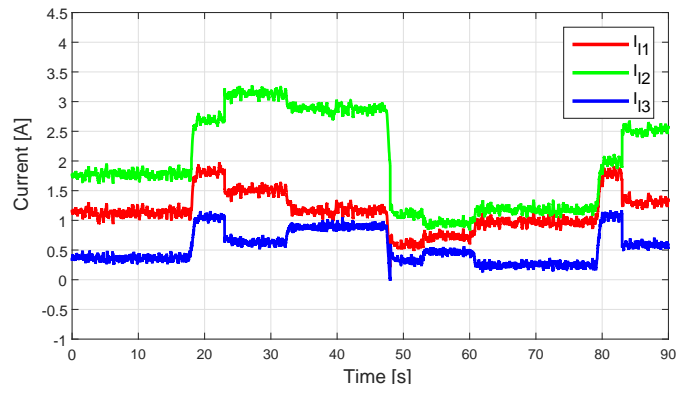

(a) DC branches currents

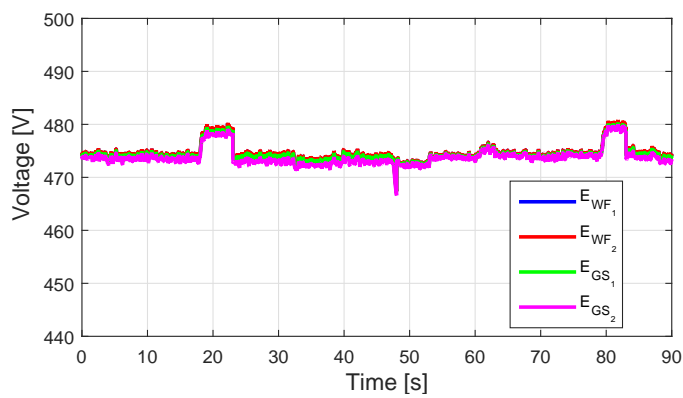

(c) DC bus voltages

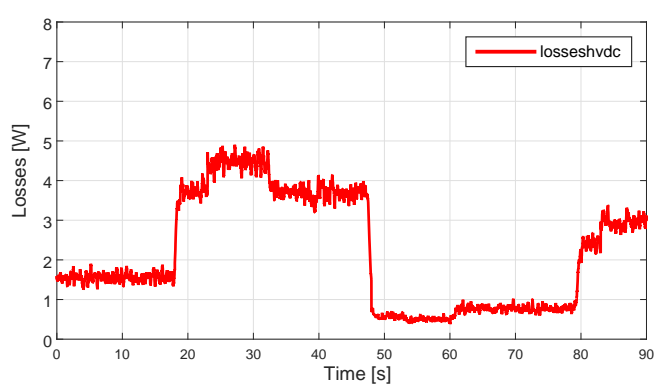

(e) HVDC grid losses

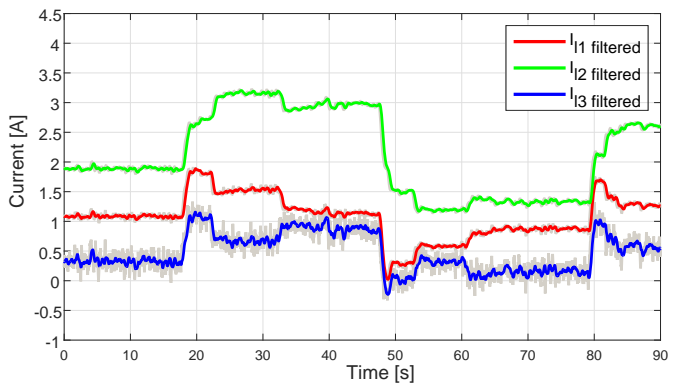

(b) DC branches currents

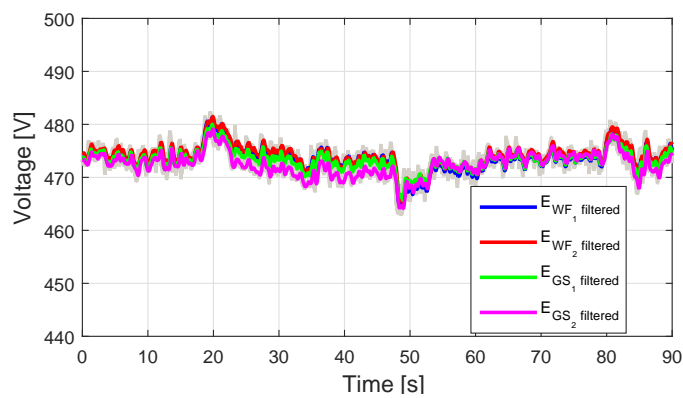

(d) DC bus voltages

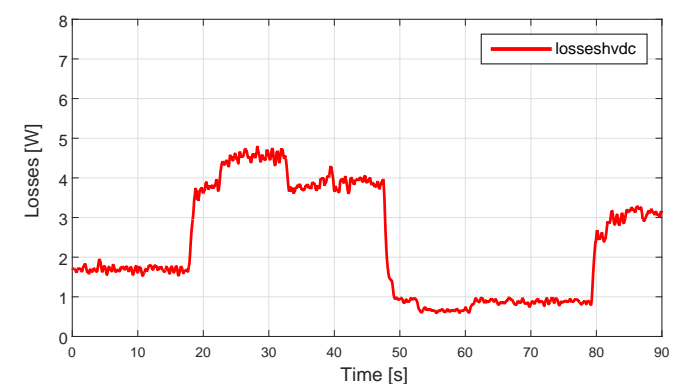

(f) HVDC grid losses

Figure 6: Case study 1: wind speed changes. Simulation results on left plots and experimental results on right plots 


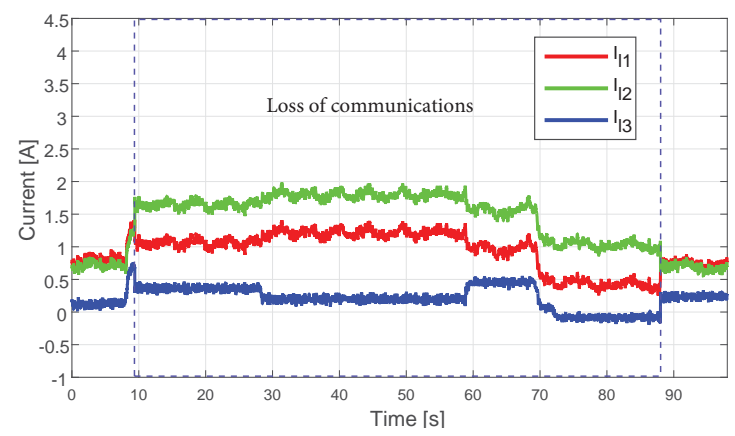

(a) DC branch currents

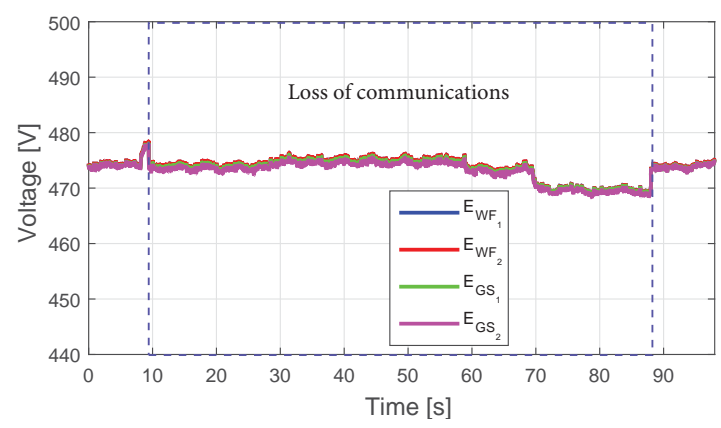

(c) DC bus voltages

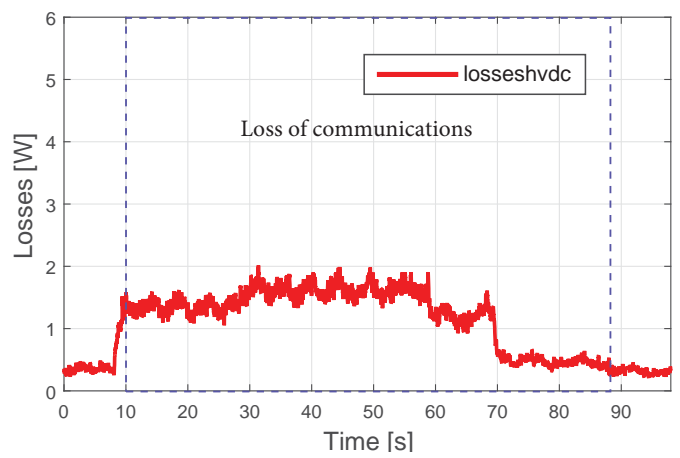

(e) HVDC grid losses

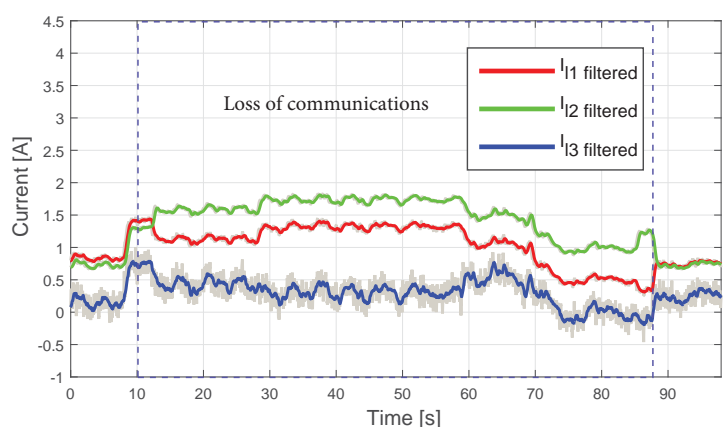

(b) DC branch currents

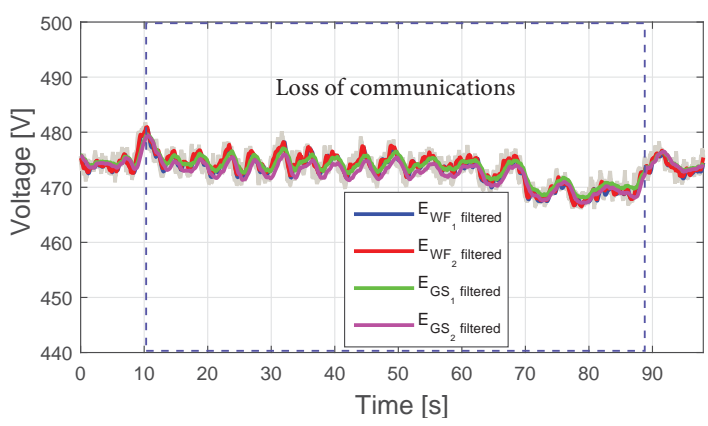

(d) DC bus voltages

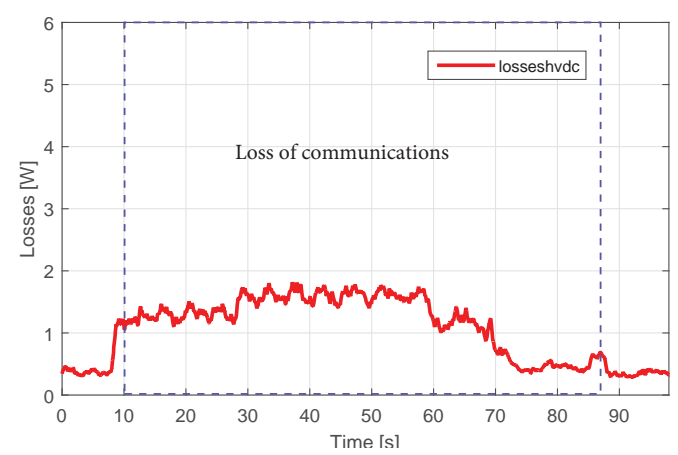

(f) HVDC grid losses

Figure 7: Case study 2: loss of communications. Simulation results on left plots and experimental results on right plots 


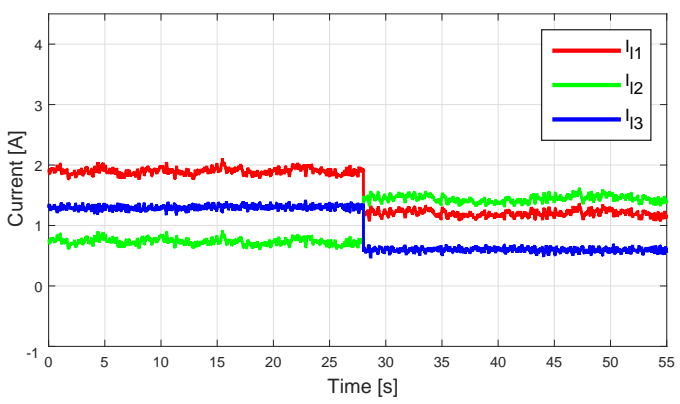

(a) DC branch currents

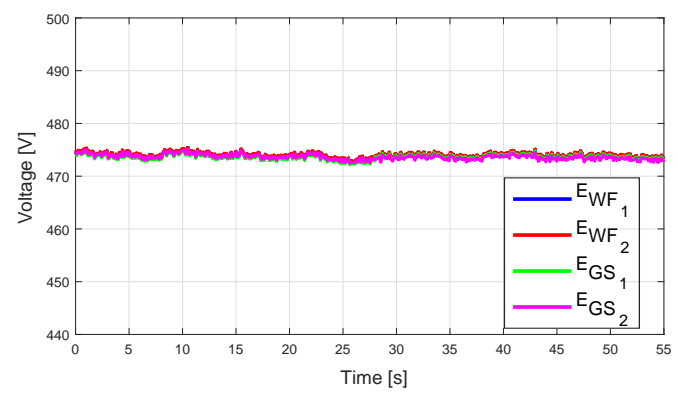

(c) DC bus voltages

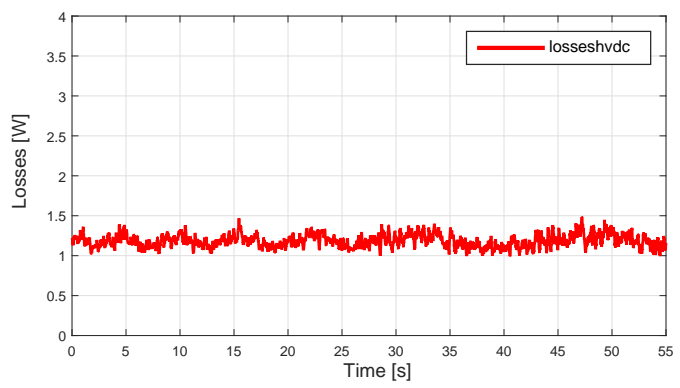

(e) HVDC grid losses simulation

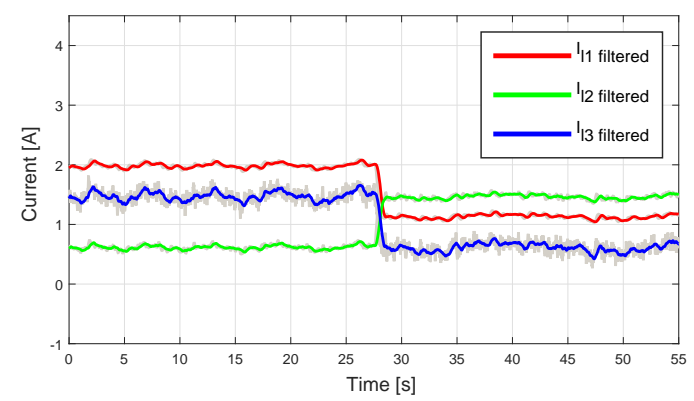

(b) DC branch currents

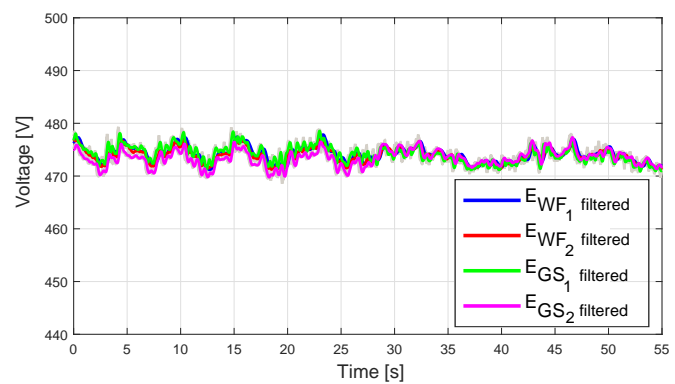

(d) DC bus voltages

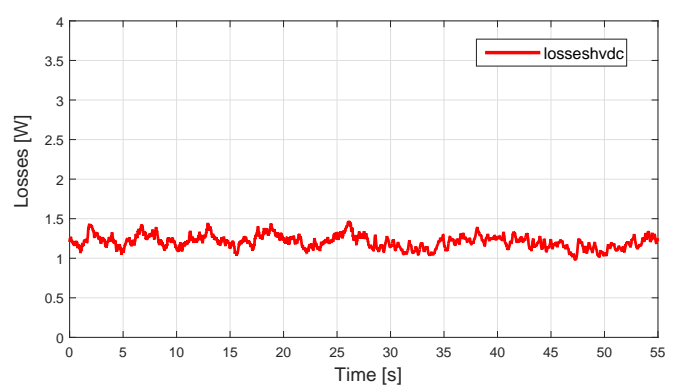

(f) HVDC grid losses

Figure 8: Case study 3: demand variation. Simulation results on left plots and experimental results on right plots 


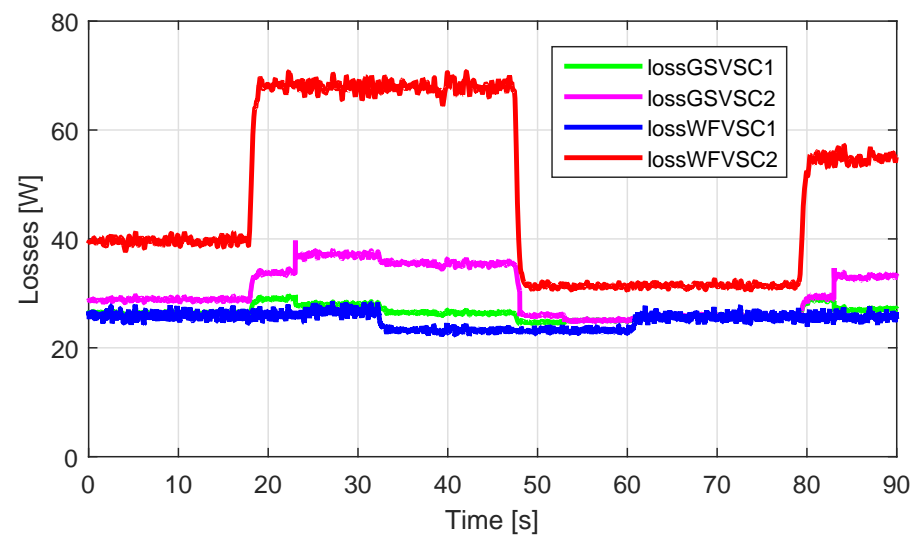

(a) Case study 1: wind speed changes

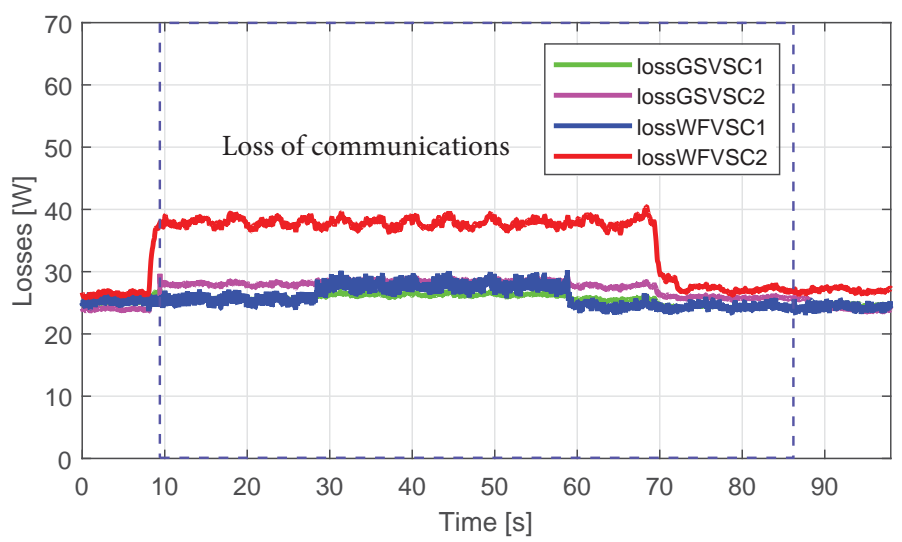

(b) Case study 2: loss of communications

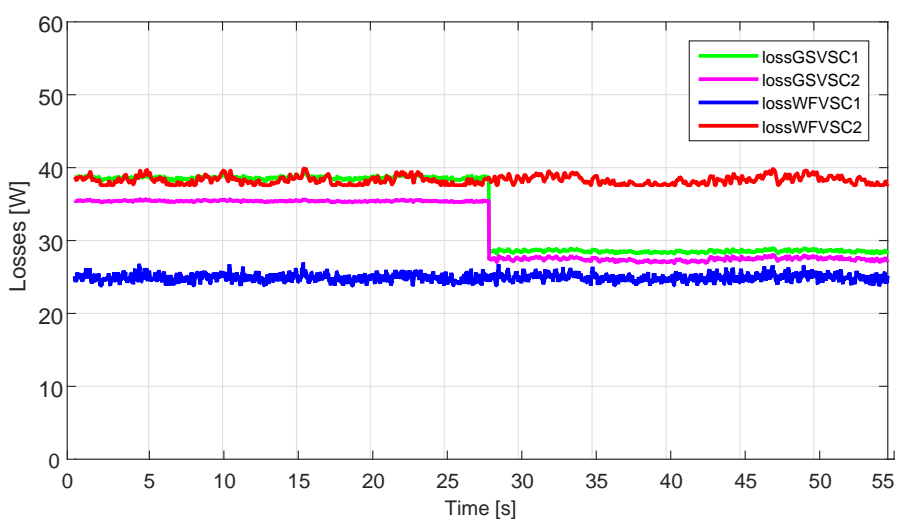

(c) Case study 3: demand variation

Figure 9: Converters losses for each case study 


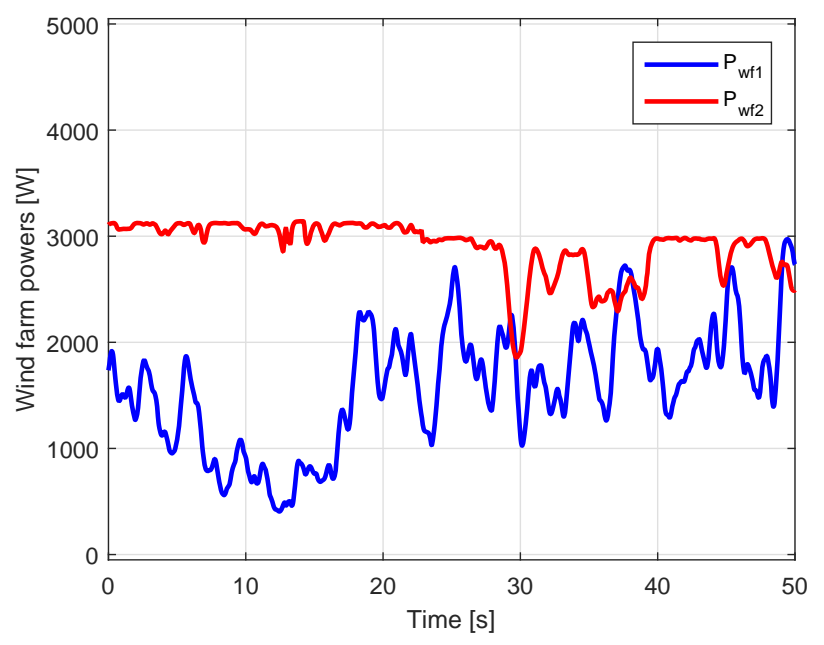

Figure 10: Wind power profiles 


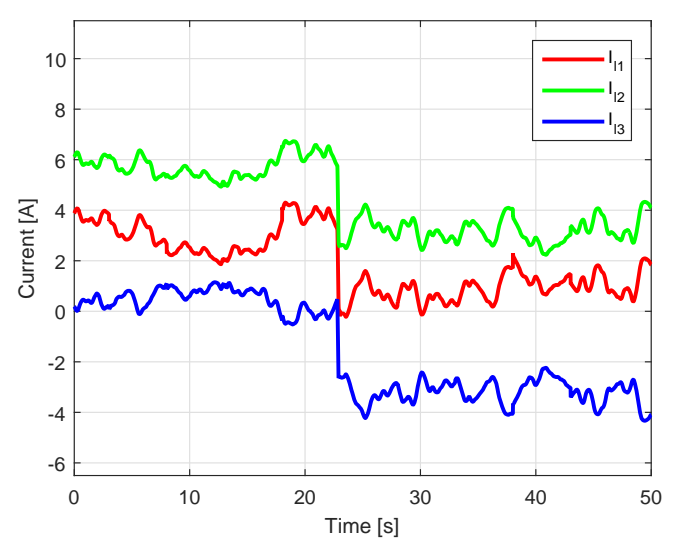

(a) DC branch currents

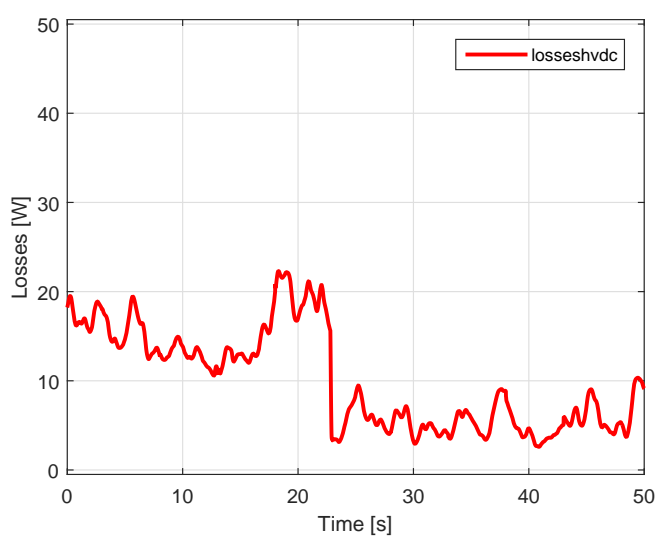

(c) HVDC grid losses

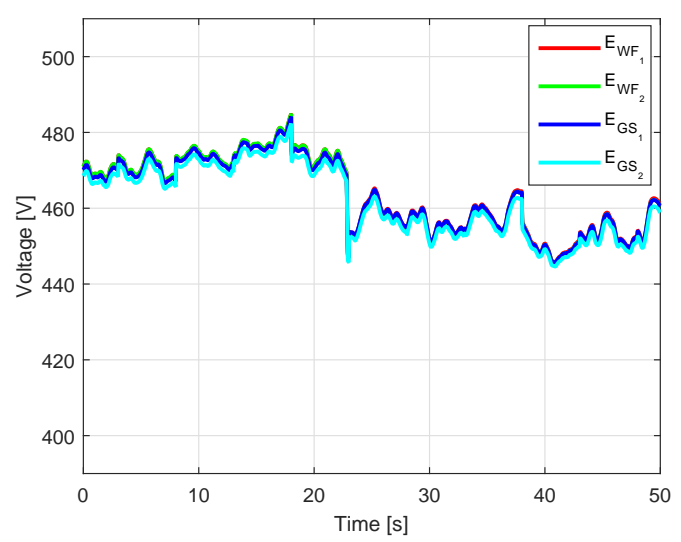

(b) DC bus voltages

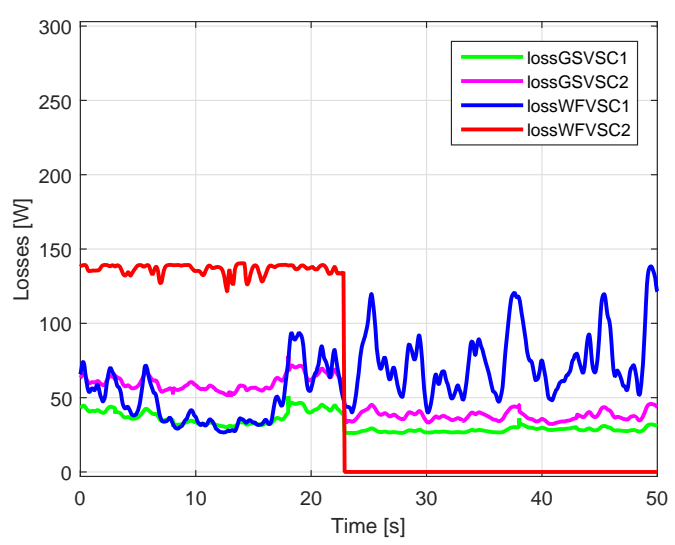

(d) Converter losses

Figure 11: VSC disconnection 


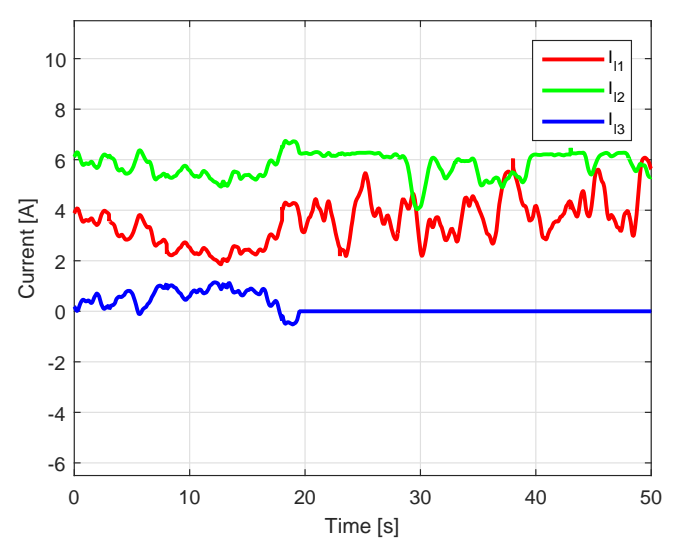

(a) DC branch currents

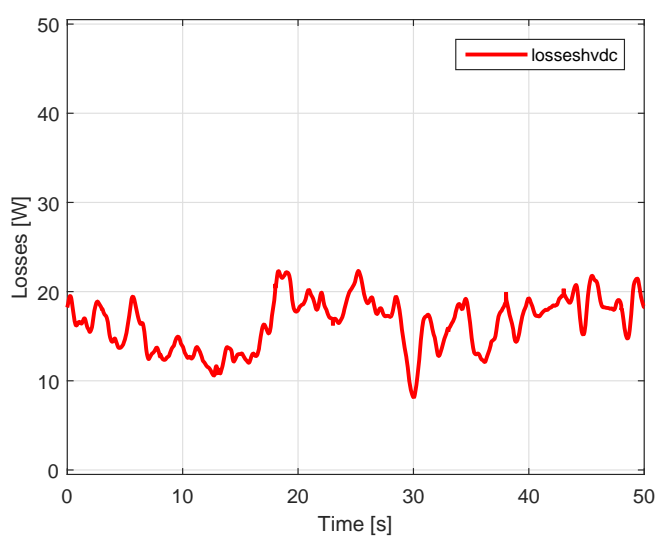

(c) HVDC grid losses

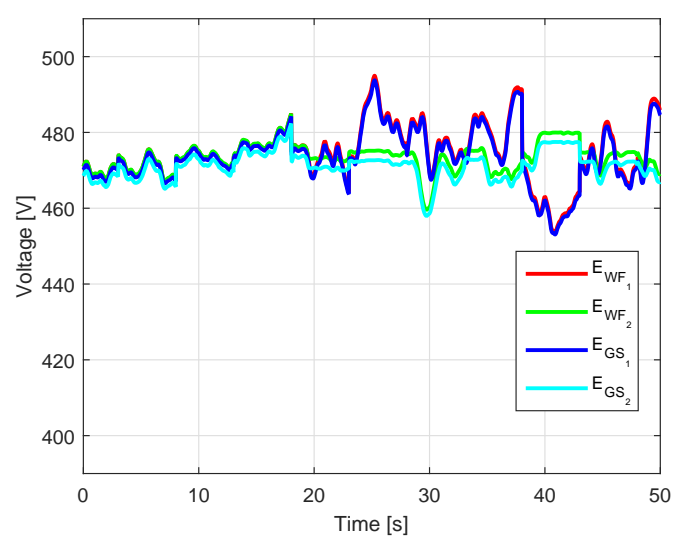

(b) DC bus voltages

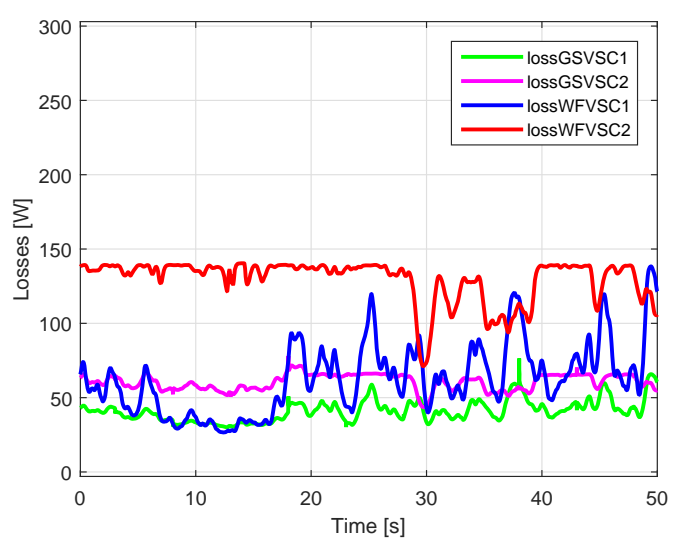

(d) Converter losses

Figure 12: Cable disconnection 


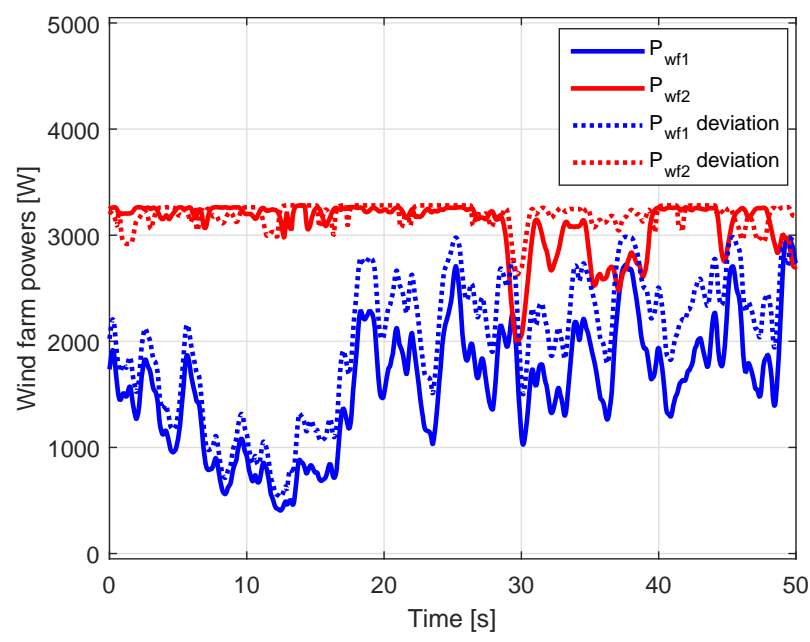

Figure 13: Wind power profiles 


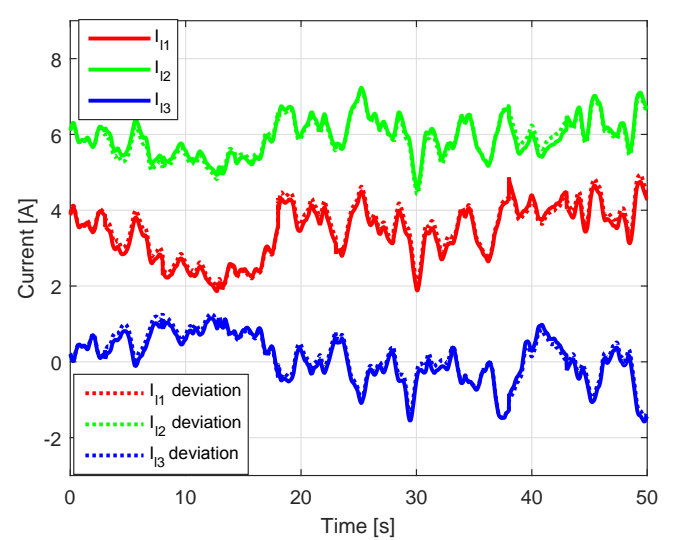

(a) DC branch currents

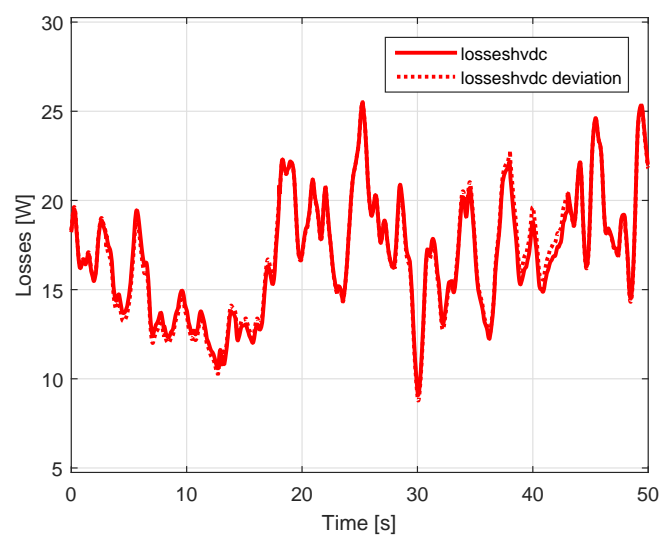

(c) HVDC grid losses

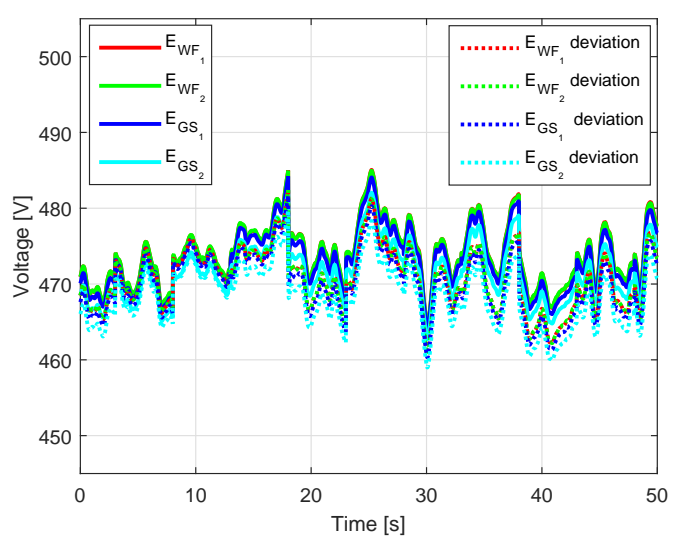

(b) DC bus voltages

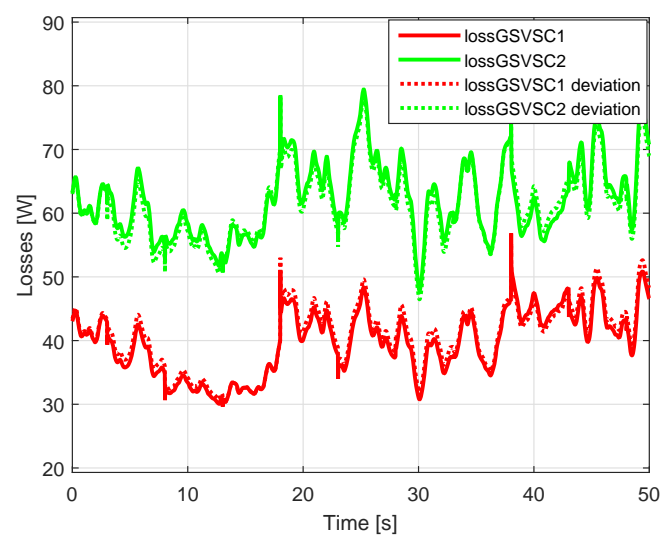

(d) Losses in grid side converters

Figure 14: Wind power variability and uncertainty effect 


\section{List of Tables}

$1 \quad \mathrm{VSC}$ characteristics $[28] \ldots \ldots \ldots \ldots \ldots$

2 DC grid resistances $[28] \ldots \ldots \ldots \ldots \ldots \ldots$ 


\begin{tabular}{|c|c|}
\hline Parameter & Value \\
\hline DC rated voltage & $800 \mathrm{~V}$ \\
AC rated current & $15 \mathrm{~A}$ \\
Maximum switching frequency & $20 \mathrm{kHz}$ \\
Coupling inductance & $4.6 \mathrm{mH}$ \\
\hline
\end{tabular}

Table 1: VSC characteristics [28] 


\begin{tabular}{|c|c|}
\hline Cable & Resistance \\
\hline Cable 1 (from VSC1 to VSC3) & $0.22 \Omega$ \\
Cable 2 (from VSC3 to VSC4) & $0.10 \Omega$ \\
Cable 3 (from VSC2 to VSC4) & $0.44 \Omega$ \\
\hline
\end{tabular}

Table 2: DC grid resistances [28] 